\title{
PERCEPÇÕES SOBRE OS CONHECIMENTOS PRÉVIOS EM MATEMÁTICA NOS ANOS INICIAIS E POSSÍVEIS CAMINHOS
}

\author{
Zulma Elizabete de Freitas Madruga ${ }^{1}$ \\ Mônica da Silva Gallon² \\ Carla Melo da Silva ${ }^{3}$
}

\section{RESUMO}

Esse artigo tem por objetivo analisar como um grupo de estudantes de Pedagogia na modalidade EaD de uma Universidade privada do Sul do Brasil compreende os conhecimentos prévios em Matemática nos anos iniciais, e possíveis estratégias para seu mapeamento. A investigação teve por base 83 respostas para um questionamento proposto em um fórum online, integrante de uma disciplina do referido curso. Os depoimentos foram voluntários, sem qualquer tipo de avaliação. Tratando-se de uma pesquisa qualitativa, dessas respostas foi realizada a Análise Textual Discursiva, resultando em duas categorias emergentes: valorização dos conhecimentos prévios e utilização de jogos e outros materiais concretos como facilitadores da aprendizagem. A investigação apontou a importância do diagnóstico para identificar os conhecimentos de Matemática pré-existentes nas crianças, a relevância do professor refletir sobre o que dados obtidos no diagnóstico inicial e sobre a sua prática de sala de aula, para que nesse processo de ação reflexão, contemple as necessidades de aprendizagem dos estudantes. Os resultados também sugerem a utilização de jogos e materiais concretos como facilitadores da aprendizagem e na construção do diagnóstico.

Palavras-chave: Educação Matemática. Anos iniciais. Conhecimentos prévios.

\footnotetext{
1 Doutora em Educação em Ciências e Matemática pela Pontifícia Universidade Católica do Rio Grande do Sul - PUCRS. Professora do Programa de Pós-graduação em Educação Matemática da Universidade Estadual de Santa Cruz - UESC, Ilhéus, BA. E-mail: zefmadruga@uesc.br

2 Doutoranda do Programa de Pós-graduação em Educação em Ciências e Matemática na Pontifícia Universidade Católica do Rio Grande do Sul - PUCRS. E-mail: monica.gallon@gmail.com

${ }_{3}^{3}$ Doutoranda do Programa de Pós-graduação em Educação em Ciências e Matemática na Pontifícia Universidade Católica do Rio Grande do SUl - PUCRS. Professora da Rede Estadual do Rio Grande do Sul. E-mail: carlamelodasilva2015@gmail.com
} 


\title{
PERCEPTIONS ABOUT PRELIMINARY KNOWLEDGE IN THE YEARS INITIAL AND POSSIBLE PATHWAYS
}

\begin{abstract}
This article aims to analyze how a group of Pedagogy students in the distance education modality of a private University of the South of Brazil understands the previous knowledge in Mathematics in the initial years, and possible strategies for its mapping. The research was based on 83 responses to a questionnaire proposed in an online forum in a course of the course. The testimonies were voluntary, without any type of evaluation. In the case of a qualitative research, the Discursive Textual Analysis was carried out, resulting in two emerging categories, namely: valorization of previous knowledge and use of games and other concrete materials as facilitators of learning. The investigation pointed out the importance of the diagnosis to identify pre-existing mathematical knowledge in children, the relevance of the teacher to reflect on what the diagnosis points to and about their classroom practice, so that in this process of reflection action, contemplate the Students' learning needs. The results also suggest the use of games and concrete materials as facilitators of learning and in the construction of the diagnosis.
\end{abstract}

Keywords: Mathematical Education. Early Years. Previous knowledge.

\section{PERCEPCIONES SOBRE LOS CONOCIMIENTOS PREVIOS EN MATEMÁTICA EN LOS AÑOS INICIALES Y POSIBLES CAMINOS}

\section{RESUMEN}

En este artículo se pretende analizar cómo un grupo de estudiantes de pedagogía en la modalidad de educación a distancia de una Universidad privada del sur de Brasil comprende el conocimiento previo de las matemáticas en los primeros años, y las posibles estrategias para su mapeo. La investigación se basó en 83 respuestas para una pregunta propuesta en un foro on-line, en una asignatura de la carrera. Las declaraciones son voluntarias, sin ningún tipo de evaluación. Se trata de una investigación cualitativa, el análisis se levó a cabo por medio del análisis textual del discurso, lo que ha resultado en dos categorías emergentes, de la siguiente manera: la recuperación del conocimiento y el uso de juegos y otros materiales concretos como facilitadores de aprendizaje p. La investigación señaló la importancia de un diagnóstico para identificar el conocimiento matemático preexistente en los niños, la importancia del maestro reflexionar sobre lo que los puntos de diagnóstico y sobre su práctica en aula para que el proceso de acción reflexión, pueda contemplar las necesidades de aprendizaje de los estudiantes. Los resultados también sugieren el uso de juegos y materiales concretos como facilitadores del aprendizaje y la construcción de diagnósticos.

Palabras clave: Educación Matemática. Primeros años. Conocimiento preliminar. 


\section{INTRODUÇÃO}

Uma das atividades mais importantes realizadas pelo professor no início de um ano letivo é identificar em sua nova turma os conhecimentos que cada estudante possui, os quais podem estar relacionados aos conteúdos a serem desenvolvidos por ocasião. Trata-se de uma tarefa necessária e exigente, pois requer do docente um olhar cuidadoso sobre os resultados, não permitindo julgamento ou correções em um primeiro momento, apenas um mapeamento e estabelecimento de estratégias de como irá se planejar de forma a contemplar esses conhecimentos.

Os estudantes ao ingressarem na escola possuem conhecimentos em graus diversos, de forma não fragmentada em disciplinas. São conhecimentos obtidos por meio de observações e interações com outras crianças e com a família, contato com o ambiente o qual está exposto e, também, por meio dos veículos de comunicação. Desconsiderar esses aprendizados é pensar na criança como um indivíduo sem voz ativa, disposto apenas a receber o conhecimento. Nesse sentido, a escola pode ser vista como um ambiente entediante e sem desafios que construam novas aprendizagens.

Dessa forma, o professor deve se apropriar desses conhecimentos, buscando subsídios para seu ponto de partida. Portanto, é de fundamental importância que o docente compreenda como o diagnóstico inicial pode orientar sua prática e também na reflexão sobre seu papel e sua formação.

Assim, objetiva-se analisar como um grupo de estudantes do curso de Pedagogia compreende os conhecimentos prévios em Matemática nos anos iniciais e possíveis estratégias para seu reconhecimento. Para a pesquisa, utilizaram-se respostas a um questionamento proposto em um fórum de discussão online, proposto em uma disciplina de um curso de graduação de Licenciatura em Pedagogia, na modalidade a distância, onde os depoentes participaram de forma voluntária, sem qualquer tipo de avaliação. 


\section{PRESSUPOSTOS TEÓRICOS}

\section{Os Saberes Discentes}

Os conhecimentos que cada estudante traz consigo, embora sejam na sua essência heterogêneos, são importantes para a viabilidade dos diálogos e das partilhas no processo de aprender a aprender. O professor, nessa perspectiva, está na função de assistente, coparticipe das ações. Portanto, não the cabe tentar converter ou impor algo como verdadeiro, mas conduzir os estudantes de modo que encontrem as respostas para seus questionamentos. Freire (2015, p. 28), contribui ao referir: "o educador não pode negar-se o dever de, na sua prática docente, reforçar a capacidade crítica do educando, sua curiosidade, sua insubmissão".

Os conhecimentos prévios são construções próprias de cada indivíduo, formulados quase espontaneamente, resultante de suas interações com os outros (POZO, 1998). As ideias relacionadas a determinado assunto, são em alguns casos, formuladas em períodos anteriores à escolarização. Esses aprendizados podem ocorrer em contato com a família, mídia, diálogos ouvidos ou vivenciados pelo indivíduo, ou ainda, influenciadas culturalmente ou produto de um raciocínio simples. Conforme Pozo (1998), essas construções pessoais, de ordem quase espontânea, podem se apresentar incoerentes do ponto de vista cientíico, porém, plausíveis do ponto de vista do estudante.

Outro aspecto que merece destaque é que "os conhecimentos dos alunos são bastante estáveis e resistentes à mudança, muitas vezes persistindo apesar de muitos anos de instrução científica" (POZO, 1998, p.39). Essas características são percebidas em sujeitos em diferentes faixas etárias, inclusive universitários (POZO, 1998).

Sendo assim, ignorar tais conhecimentos e partir para um ensino que percebe o estudante como uma folha em branco, pode contribuir na consolidação de ideias equivocadas sobre determinados conteúdos, não oferecendo oportunidades para que sejam substituídas ou complementadas 
ao longo de sua escolarização. De acordo com Sobral e Teixeira (2007), o fato de reconhecer a importância do conhecimento prévio dos estudantes antes de iniciar um novo conteúdo não significa dizer que este esteja sendo contemplado na estratégia de ensino do docente. De pouco adianta reconhecer o que os estudantes já sabem se não há articulação entre esses conhecimentos e os novos a serem abordados.

E sempre haverá conhecimentos prévios? Conforme Miras (1998, p. 62):

Evidentemente, numa perspectiva externa ao aluno e de forma abstrata, determinar se existem ou não conhecimentos prévios sobre um novo conteúdo de aprendizagem é uma questão difícil ou pelo menos discutível, pois dependerá de quem decide quem constitui o conhecimento prévio sobre tal conteúdo. Mas, de qualquer forma, se nos colocarmos na perspectiva do aluno, na lógica da percepção construtivista, é possível afirmar que sempre podem existir conhecimentos prévios a respeito do novo a ser aprendido, pois, de outro modo, não seria possível atribuir um significado inicial ao novo conhecimento, não seria possível a sua 'leitura' em uma primeira aproximação.

Reconhecer tais conhecimentos implica em um trabalho cuidadoso realizado pelo docente. Além do olhar atento do professor ao seu grupo, uma avaliação diagnóstica pode auxiliar nessa identificação. Para Santos e Varela (2007, p. 4), este tipo de avaliação é "constituída por uma sondagem, projeção e retrospecção da situação de desenvolvimento do aluno, dandoIhe elementos para verificar o que aprendeu e como aprendeu". O objetivo da referida avaliação é verificar os conhecimentos anteriores e em que medida foram aprendidos, e ainda auxiliar o professor no planejamento quanto as dificuldades encontradas. Santos e Varela (2007) afirmam que a partir da avaliação diagnóstica é que deve ser organizado o plano de ação do docente, em conjunto com os estudantes, e que esta, obrigatoriamente, implica em uma tomada de decisão.

No planejamento das ações subsequentes, é importante o professor acreditar que o estudante é capaz, por meio de propostas significativas, motivá-los em suas aprendizagens. Quando Freire $(2015$, p. 31) afirma que "ensinar exige respeito aos saberes dos educandos", instiga a reflexão sobre 
a importância de significar o que o estudante considera como relevante e, para tanto, o professor necessita perceber seu papel docente, não apenas como uma "tarefa de ensinar conteúdos, mas como ensinar a pensar certo". Nesse sentido, Paulo Freire aponta que o fazer diferente, qualificando sua prática no cotidiano, exige do docente uma atitude criativa, instigadora, curiosa e humilde, agindo de forma positiva, valendo-se não apenas ao professor que assim o faz, mas ao estudante em partilha com esse educador (FREIRE, 2015).

Numa perspectiva construtivista, aprender significativamente "é um processo em que integra, modifica e estabelece relações de saberes que já possuímos a cada aprendizagem que realizamos" (SOLÉ; COLL, 1998, p.20). A escola enquanto ambiente de desenvolvimento social e interpessoal dos estudantes é também responsável por tornar cada um desses sujeitos um ser único, com ideias próprias, criativo, crítico e potencialmente capaz cognitivamente. Portanto, é competência da escola desenvolver no estudante a capacidade de reconstruir significados, em relação a conhecimentos que compõe o currículo escolar (SOLÉ; COLL, 1998).

A escola como um ambiente que propõe 0 ressignificar da aprendizagem, tem nos docentes, a função de identificar o que os estudantes possuem de conhecimentos e propor formas de potencializá-los.

\section{O Ensino de Matemática e o professor iniciante}

A Matemática, enquanto ciência deve ser vista em um permanente processo de reconstrução. Ainda é vigente na sociedade a imagem de uma disciplina dura, maçante, difícil e que requer apenas quadro e giz. Mas a prática pedagógica da Matemática tem se mostrado flexível, com a inserção de novas tecnologias e recursos concretos manipuláveis e espaços variados para o ensino de Matemática, que possibilitam maior compreensão do que se quer ensinar. Isso permitirá que o estudante nas diferentes faixas etárias, explore conhecimentos matemáticos que nem sempre são vistos com clareza em situações cotidianas. 
De acordo com Alves e Morais (2006, p. 338),

Considera-se recurso didático todo o ato do professor que promova a difusão do conhecimento e o torne compreensível na ação de ensinar. Assim, um recurso didático não é o conhecimento em si, mas o que ajuda a sua legitimidade, facilitando a sua intuição, aceitação e compreensão pelo aluno.

O processo de ensino e aprendizagem de Matemática deve ser visto pelo estudante como uma possibilidade de explorar o desconhecido, resolver problemas, compartilhamento de ideias e comunicação do aprendido. Isso permitirá ao professor, organizar e sistematizar o conhecimento que pretende desenvolver.

Pensando em aproximar a disciplina à realidade do estudante, podese fazer uso de recursos didáticos variados no ensino da Matemática, todavia, faz-se necessário que o professor identifique as dificuldades existentes. Conforme a Base Nacional Comum Curricular - BNCC (BRASIL, 2016, p. 132),

O ensino de Matemática visa a uma compreensão abrangente do mundo e das práticas sociais, qualificando a inserção no mundo do trabalho, que precisa ser sustentada pela capacidade de argumentação, segurança para lidar com problemas e desafios de origens diversas. Por isso, é fundamental que o ensino seja contextualizado e interdisciplinar, mas que, ao mesmo tempo, se persiga o desenvolvimento da capacidade de abstrair, de perceber o que pode ser generalizado para outros contextos, de usar a imaginação.

No Ensino Fundamental, em especial nos anos iniciais, espera-se que os estudantes aprimorem seus conhecimentos desenvolvidos na Educação Infantil, atrelados aos seus saberes pré-existentes. Pois no que tange a Matemática dos anos finais do Ensino Fundamental, enseja-se 0 amadurecimento dos conceitos anteriormente aprendidos pelos estudantes. Segundo a Base Nacional Comum Curricular (BRASIL, 2016, p.400):

É assim que a Matemática escolar se constitui, acompanhando o desenvolvimento dos estudantes, por meio de suas sucessivas descobertas de possibilidades e conceitos que passam a fazer sentido para a resolução de novos problemas. [...] que contribui não apenas para aumentar o raciocínio lógico, mas, principalmente, o 
poder de resolver problemas que dependem de um novo tipo de compreensão das informações disponíveis para gerar modelos de resolução.

Os conteúdos escolares não devem ser trabalhados de modo fragmentado, "também não serão esgotados em um único momento da escolaridade, mas pensados numa perspectiva em espiral, ou seja, os temas são retomados e ampliados ao longo dos anos de escolarização" (BRASIL, 2012, p.25). Nesse sentido, o professor deve estar ciente que precisa valorizar e aprofundar os conhecimentos dos estudantes para que o processo em espiral da aprendizagem ocorra de forma satisfatória.

A formação do professor - seja ela inicial ou permanente - tem um papel fundamental na tomada de consciência quanto ao seu papel por meio de constante estudo e reflexão sobre seus fazeres pedagógicos de modo autônomo. Perrenoud (2002) e Nóvoa (1992) concordam que o educador reflexivo faz de sua ação fator de constante mudança, que the dá condições de aprender permanentemente pela análise da própria prática e, portanto, Ihe torna um profissional diferenciado. Segundo Alarcão (2011), a capacidade de refletir sobre seus atos e pensamentos, qualificam o professor reflexivo como um ser criativo e não um simples repetidor de ideias e práticas. O ser reflexivo constrói seu conhecimento pedagógico, produzido das suas atitudes reflexivas individuais ou entre pares por meio do trabalho em equipe, baseada em habilidades e atitudes, numa "formação a partir de dentro" (IMBERNÓN, 2009, p.22).

Quem vai transformar o modo de aprender e ensinar numa experiência significativa, tornando-a produtiva e alegre é o professor. Dessa forma, é importante a inserção de estratégias que instiguem a formação de um sujeito que pensa sobre sua prática pedagógica e se preocupa em reconstruir de modo qualificado as suas ações ao longo da formação inicial e continuada da carreira docente. 


\section{Jogos como forma de ensinar e aprender Matemática}

As brincadeiras com uso de jogos permeiam a vida das pessoas desde a infância até a fase adulta. Se estes estão presentes em diversas fases da vida, por que não os utilizar como ferramenta de aprendizagem? Partindo desse pressuposto, os jogos são um recurso didático-pedagógico relevante para a aprendizagem da Matemática, considerando que esses promove a relação do concreto com o abstrato.

Nesse sentido, o jogo pode fazer parte do planejamento cotidiano do professor, orientado à sua intencionalidade, aplicado como estratégia de diagnóstico sobre o que os alunos já sabem ou mesmo para observar se algum conteúdo necessita ser revisto, ou melhor desenvolvido. O professor deve ter ciência das potencialidades do jogo escolhido para que consiga intervir sobre as questões relacionadas à Matemática (e outras disciplinas que podem estar associadas) que poderão emergir durante as partidas em sala de aula.

Segundo a BNCC (BRASIL, 2016, p. 252), no que tange o ensino da Matemática, "os jogos, brincadeiras, explorações de espaços e materiais diversos oferecem contextos propícios ao desenvolvimento de noções matemáticas".

É necessário ressaltar que o jogo como instrumento meramente lúdico, não agregará significado no processo de ensino e aprendizagem. Portanto, esse deve estar vinculado aos conteúdos a serem aprendidos, bem como, com objetivos específicos a fim de melhor compreender e sistematizar a aprendizagem.

Destaca-se também a característica que os jogos, em sua maioria, são praticados em grupos favorecendo assim o processo de socialização na aprendizagem. De acordo com Lopes (2014, p.35):

[...] as crianças têm seu potencial de aprendizagem melhor aproveitado quando têm oportunidade de trabalhar em pequenos grupos colaborativos, discutindo e explicando umas às outras o porquê de suas estratégias e de suas descobertas. Esse processo de troca entre os alunos é importante para que pensem sobre uma 
tarefa, um problema matemático, uma ideia ou procedimento de múltiplas perspectivas, o que contribui para o desenvolvimento de seus processos de argumentação e comunicação matemática.

A criança tem por natureza a curiosidade, um fator que deve ser explorado pelo professor. Propor jogos em sala de aula, em especial na aprendizagem matemática, pressupõe a resolução de problemas e construção de significados. Com relação a isso Lopes (2014, p.65), orienta:

\begin{abstract}
O papel do professor não é apenas da oferta do jogo, mas estar junto, realizar intervenções e mediações no processo do jogo, realizar provocações (jogar junto é uma estratégia interessante); estar junto, acompanhando a realização da atividade pela criança e pelo grupo, avaliando as capacidades e necessidades, estimulando a verbalização das estratégias utilizadas, exteriorizando seus pensamentos, instigando outras possibilidades. Estar junto ao desenvolvimento do jogo da criança é sempre uma rica oportunidade de avaliação da aprendizagem, de compreensão sobre seus processos de aprendizagem e desenvolvimento.
\end{abstract}

Nesse sentido, o jogo permite ao professor compreender como os sujeitos se desenvolvem cognitivamente. Assim como, o contexto social em que a criança está inserida é um excelente ponto de partida para as aprendizagens, contudo, há a necessidade do professor ter um controle, estipulado por regras, que permitam reconhecer a aprendizagem com a atividade lúdica. $O$ jogo precisa ter sentido para o estudante, que ele possa estabelecer relações com os conhecimentos matemáticos e isso the possibilite uma maior compreensão dessa ciência.

\title{
PROCEDIMENTOS METODOLÓGICOS
}

A pesquisa é de cunho qualitativo (BOGDAN; BIKLEN, 1994), utilizando como instrumento de coleta de dados 83 depoimentos de 70 estudantes do curso de Licenciatura em Pedagogia, na modalidade à distância de uma universidade privada do Sul do Brasil. A coleta de dados se deu por meio da seleção de postagens em um fórum de discussão, com respostas espontâneas de cada cursista para um questionamento proposto em um espaço assíncrono, integrante uma disciplina do referido curso. Os depoimentos foram voluntários, sem qualquer tipo de avaliação. 
Para o processamento dos dados, utilizou-se a Análise Textual Discursiva - ATD. Segundo Moraes e Galiazzi (2013, p.11), esse tipo de análise segue em três etapas: a) desconstrução e unitarização (unidades de sentido); b) categorização (relações entre o que foi unitarizado); c) construção dos metatextos, a partir das interpretações do investigador. $\mathrm{Na}$ sequência, far-se-á uma síntese do que consiste em cada uma dessas etapas, apontando os aspectos fundamentais de cada uma.

a) Desconstrução e unitarização: Em etapa inicial, após constituição do corpus de análise (seleção e organização do material a ser submetido à investigação, com base nos objetivos da pesquisa), fragmenta-se o texto em unidades de significado, com vistas ao problema de pesquisa.

O processo de unitarização necessita da fidelidade do pesquisador em relação ao que consta no corpus da pesquisa, "uma atitude fenomenológica de deixar que o fenômeno se manifeste" (MORAES; GALIAZZI, 2013, p.53).

b) Categorização: Essa etapa resulta do processo de organização e agrupamento das unidades de significado, podendo surgir de duas situações: forma objetiva e dedutiva - chamada de categoria a priori; e forma indutiva e subjetiva - denominada de categorias emergentes (MORAES; GALIAZZI, 2013). Esse processo exige potencial criativo, atento e organizado do investigador.

c) Metatextos: A escrita de metatextos irá enunciar a compreensão do pesquisador sobre o fenômeno de investigação, baseada nas categorias elegidas no estágio anterior. Nesta etapa, o processo de escrita trama a descrição do fenômeno, a interpretação realizada pelo pesquisador e, dessa forma, há o surgimento do novo (MORAES; GALIAZZI, 2013). 
Nesta pesquisa, adotou-se como corpus, todas as postagens realizadas no fórum, fragmentando as unidades de sentido, posteriormente agrupadas em subcategorias e, posteriormente, em categorias. Optou-se pelo emprego de categorias emergentes. Para melhor compreensão do contexto dado pelos participantes, preferiu-se exibir trechos dos depoimentos.

\title{
RESULTADOS E DISCUSSÃO
}

Foram analisadas 83 postagens de um fórum de discussão online, com participação de 70 estudantes, integrantes de um curso de Licenciatura em Pedagogia na modalidade a distância. Este espaço de aprendizagem assíncrono ocorreu como parte de uma disciplina intitulada: Metodologia do Ensino da Matemática. Para instigar a colaboração dos graduandos neste fórum semanal ${ }^{4}$, o tutor da disciplina ${ }^{5}$ postou o seguinte texto:

\begin{abstract}
"Antes de começar a ensinar matemática é sempre bom analisar como está o aprendizado de seus alunos, o que eles sabem e o que não sabem. Assim você pode partir de uma base e, muitas vezes, nós podemos nos surpreender com o que as crianças sabem. Avalie as noções elementares de adição e subtração de seus alunos e, considerando que a construção do conhecimento lógicomatemático se dá por meio das ações que o sujeito realiza sobre os objetos, preocupe-se em identificar até que ponto as crianças são capazes de estabelecer relações entre as operações efetuadas rotineiramente no contexto escolar e as ações materiais de reunir/tirar objetos. Você consegue imaginar alguma atividade para aplicar essa metodologia? Reflita e compartilhe com seus colegas" (Participante 0).
\end{abstract}

A partir desta questão norteadora, o tutor instiga a discussão a respeito da temática pelos alunos do curso. Conforme análise dos depoimentos coletados, emergiram duas categorias: valorização dos conhecimentos prévios e utilização de jogos e outros materiais concretos como facilitadores da aprendizagem, descritas a seguir:

\footnotetext{
4 Os fóruns desta disciplina ocorriam semanalmente. Em cada fórum, havia uma questão disparadora postada pelo tutor da disciplina. Estas questões tinham temas distintos e ocorriam em sintonia com os conteúdos discutidos nas aulas da semana.

5 Chamou-se o tutor de Participante 0 , pois sua contribuição inicial serviu apenas como questão motivadora para as discussões do fórum.
} 
Categoria 1: Valorização dos conhecimentos prévios

Os licenciandos argumentam que é necessário valorizar os conhecimentos prévios dos estudantes por meio da aplicação de avaliações diagnósticas. Esta primeira categoria abarca duas subcategorias:

\title{
- Sondagem/diagnóstico
}

Há consenso que este diagnóstico é necessário, e se observa uma tentativa em indicar caminhos para instrumentalização desses professores. Em seus depoimentos emergem elementos como bateria de testes, avaliação individual, grupos, jogos, e atividades que valorizem o emprego da Matemática no cotidiano:

\begin{abstract}
"Fazer um diagnóstico para saber o que o aluno já conhece é necessário, pois uma sondagem com os alunos antes de iniciar um conteúdo é fundamental" (Participante 6).

"Apurar o conhecimento prévio dos alunos agiliza o aprendizado, pois muitos conceitos o aluno pode já possuir, necessitando por vezes apenas uma melhor lapidação. A Matemática como todas as outras disciplinas deve valer-se de ferramentas diagnósticas, a sugestão de utilizar jogos para tal diagnóstico é extremamente bem-vinda e eficaz" (Participante 9).
\end{abstract}

"Considerar o que o aluno já sabe é dar valor a bagagem de conhecimento que são como suporte para que outros conceitos sejam aplicados e construídos" (Participante 11).

"Deve fazer primeiro uma pesquisa para saber o que ele já sabe do seu dia com a família e que ele usa e faz parte da Matemática que já conhece do seu cotidiano" (Participante 33).

"É muito importante resgatar os conhecimentos prévios dos alunos antes de iniciar os conteúdos matemáticos, trazer situações do cotidiano ajuda na melhor compreensão para resolução de problemas" (Participante 67).

"Primeiramente, fazer uma 'bateria de testes' para ver o que os alunos sabem. Em seguida, aplicar atividades em grupos [...] com o objetivo de despertar o interesse dos alunos" (Participante 68).

Com base nesses depoimentos, percebe-se a importância atribuída à avaliação diagnóstica. Nesse sentido, Boggino (2009, p. 82) afirma que: 
genuínas e significativas, supõe questionar os esquemas e estruturas cognitivas e os conhecimentos prévios que os alunos têm relativamente à matéria que se quer ensinar.

Embora os futuros professores compartilhem da opinião que há necessidade de se fazer esse diagnóstico, e arriscam-se a sugerir maneiras de efetivá-los em sala de aula, as postagens não indicam um planejamento a partir dos resultados obtidos. Verifica-se que não está claro para o graduando o real papel desse diagnóstico. De acordo com Jussara Hoffman (apud MOÇO, 2010), a avaliação inicial tem papel fundamental na constituição de um olhar para cada estudante e, a partir disso, auxiliar o docente no planejamento das aulas com base nas reais necessidades para o aprendizado do grupo.

Nos relatos, evidencia-se que o licenciando tem a consciência do que deve conhecer, mas não sabe exatamente como e, além disso, não sabe ao certo o que fazer com estas avaliações. Em nenhum depoimento há um apontamento sobre o que será feito com o conhecimento adquirido por meio do diagnóstico. Anderson Moço (2010) afirma que não é qualquer atividade que vai fornecer um bom diagnóstico. Portanto, o professor necessita compreender o nível de aprendizado que as crianças se encontram e, com base nisso, planejar situações-problema que venham a auxiliar na sua percepção quanto ao conhecimento individual do grupo. A partir disso, o docente precisa tomar decisões sobre o que fazer, pois, conforme Santos e Varela (2007), a função da avaliação diagnóstica envolve uma tomada de decisão posterior em favor do ensino.

- Reflexão sobre conhecimentos prévios

Nesta subcategoria, os licenciandos discutem a importância do material concreto, considerando a realidade dos estudantes e valorizando suas estratégias espontâneas:

"Para avaliar o que os alunos já sabem em soma e subtração o professor, por exemplo, pode utilizar objetos simples do dia-a-dia, bem como, lápis, borracha, livros, cadernos, canetas, bolinhas, 
dados, etc. O professor pode fazer grupos e dar aos alunos os materiais, para os mesmos fazerem a representação com os objetos das operações" (Participante 36).

"O diagnóstico é fundamental para saber o nível de conhecimento de cada aluno. Esse trabalho pode ser realizado em duplas ou trios, pedir para os alunos trazerem vários objetos ou brinquedos e fazer um dia do mercado, com situações diferenciadas. As notas serão de dinheiro de brincadeira" (Participante 48).

"Conhecer o processo psicológico da criança, a efetivação da aprendizagem nos anos iniciais, a valorização dos conhecimentos culturais, trabalhar os diversos conteúdos com material concreto palpável e, jogos educativos" (Participante 52).

"[...] tiveram algum trabalho desenvolvido ou pelos pais ou pelos estudos anteriores, [...] as atividades podem partir desde objetos do convívio comum dos alunos como figurinhas, carrinhos ou até mesmo balinhas" (Participante 57).

"[...] as primeiras experiências de Matemática na escola devem estar baseadas no aproveitamento do conhecimento que a criança traz consigo; no manuseio de objetos, observação e ações; na utilização do material concreto, de modo a favorecer o pensamento intuitivo. Muitas atividades podem aproximar as crianças da Matemática como: manuseio de materiais, reconhecimento e contagem de objetos, organizar e brincar com tampinhas, blocos, jogos, dominós. O ensino das primeiras noções matemáticas deve consistir numa relação entre os conhecimentos já adquiridos pela criança e as novas tarefas. As atividades devem ser escolhidas levando-se em conta as especificidades do aluno, iniciando do concreto com vistas ao abstrato" (Participante 59).

"Sabemos que toda criança traz consigo um conhecimento prévio, seja ele o mais simples possível, assim, cabe ao professor investigar qual o nivel de conhecimento de seu aluno acerca de determinado conteúdo, para que possa elaborar possiveis estratégias de intervenção na intenção de aprimorar ou propiciar a construção do conhecimento por parte do aluno [...]. Utilizar àquilo que é próprio do cotidiano dos alunos, torna a aprendizagem muito mais significativa e fascinante, [...] valorizar as estratégias espontâneas dos alunos quando se propõem atividades matemáticas concretas. [...] Após o trabalho com materiais concretos (palitos, pedras, manipuláveis, material dourado, entre outros) podemos levar os alunos ao laboratório de informática para realizarem atividades que visam à exploração e desenvolvimento dos conceitos" (Participante 66).

Para realização do diagnóstico, os licenciandos apontam algumas sugestões, principalmente no que se refere aos materiais concretos (elementos comuns em sala de aula e outros trazidos de casa); jogos (bingo, 
dados e jogos com tabuleiros são recorrentes nos depoimentos). Estas sugestões vêm ao encontro das afirmações de Bottas e Moreira (2013):

\begin{abstract}
Uma das formas de promover diferentes experiências de aprendizagem matemática enriquecedoras é através do uso de materiais didáticos, os quais assumem um papel ainda mais determinante por força da característica abstrata da Matemática. Apesar da utilização do material não determinar por si só a aprendizagem, é importante proporcionar diversas oportunidades de contato com materiais para despertar interesse e envolver o aluno em situações de aprendizagem matemática (BOTTAS; MOREIRA, 2013, p.254).
\end{abstract}

Os depoimentos indicam que há uma conscientização dos futuros professores no sentido de utilizar métodos não tradicionais. Embora alguns ainda mencionem bateria de testes (Participante 68) como eficaz para avaliação, a maioria indica a utilização de uma metodologia diferenciada e, principalmente, o uso de materiais manipuláveis. Os dados levantados por meio da avaliação são sempre provisórios, pois o estudante encontra-se em constante processo de aprendizagem (SANTOS; VARELA, 2007). Nesse sentido, é importante também o professor ter ciência que um único instrumento diagnóstico não fornecerá um mapa fiável dos conhecimentos prévios do grupo. Para Luckesi (2002), a função diagnóstica da avaliação constitui um momento dialético para o aumento da autonomia e para a competência. E, na medida em que o docente vai testando seu grupo, também deve refletir sobre de que forma ele também está sendo testado, buscando subsídios para interpretar e elaborar estratégias que auxiliem no aprendizado coletivo.

Categoria 2: Utilização de jogos e outros materiais concretos como facilitadores da aprendizagem

Esta categoria, também organizada em duas subcategorias, apresenta a ênfase dos licenciandos para a utilização de material concreto, principalmente jogos, registrando-se a presença em 21 depoimentos 
sugerindo o trabalho com diferentes tipos de jogos, especialmente de tabuleiros, para realização do diagnóstico inicial dos estudantes.

As falas dos estudantes de Pedagogia foram divididas em duas subcategorias:

\section{- Exemplos de práticas}

As postagens apresentam modelos variados, onde os graduandos compartilham experiências diversas, e apontam caminhos para a construção de um diagnóstico inicial.

"[...] Exemplo de um jogo que se pode trabalhar essas noções de adição e subtração é O JOGO DO BARBANTE COM PREGADOR. Joga-se o dado e, de acordo com o numeral, e seguindo as orientações do professor, ou tira ou coloca pregadores no barbante, fazendo assim a contagem" (Participante 8).

"Ensinar Matemática aos alunos a partir dos jogos lúdicos e brincadeiras com objetos (material dourado, palitos coloridos, tampinhas, sementes, jogos, botões, caixas, etc.) são as melhores maneiras de estabelecer relações entre as operações efetuadas (adição e subtração). As atividades para aplicar essa metodologia com objetos (bingo, montar um mercado, jogo da trilha, boliche, amarelinha, dominó, varetas, jogo com cartas, etc.)" (Participante14).

"Dependendo da faixa etária dos alunos, há várias atividades a serem desenvolvidas. Pode-se fazer uma grade no chão, com seis quadrados, dividi-los em grupos de cinco alunos e fazê-los deslocarem-se para outro grupo e ver com quantos integrantes cada grupo ficou depois da troca. Alterna-se a quantidade de pessoas que se deslocam em cada troca. É uma atividade de soma e subtração partindo da observação" (Participante 32).

"Acho interessante pegar anúncios de jornal, onde temos os planos de pagamento, entrada e mais tantas prestações. Pode ser feito com anúncio de carro, imóvel, eletrônicos e etc. Exemplo: O carro custa 60 mil, entrada 20 mil e o restante em 24 parcelas, temos então uma conta de subtração, uma de divisão e depois a multiplicação para tirar a prova" (Participante 16).

"Minha contribuição sobre este assunto, é referente a minha experiência no Ensino Fundamental com Educação Musical. Trabalhar com canções que enfatizem a lateralidade, a contagem dos tempos rítmicos, os compassos musicais é uma forma de também aprender Matemática. Um recurso seria as cantigas de roda, por exemplo, a canção 'Escravos de Jó', em que trabalhada em sentido de ciranda (circular) e é cantada, cuja a letra indica as ações de pôr ou tirar um elemento (objeto: pode ser um copo ou pedra). Esta 
atividade além de estimular a atenção a letra da música, permite de maneira lúdica compreender como se pode adicionar ou subtrair algo mas, para isso, não se pode também perder o ritmo da canção". (Participante 45).

"Pensei na utilização de uma fita no chão, ao tempo em que o professor faz perguntas a respeito do assunto, eles se aproximam até a fita (quem sabe a resposta) ou permanecem parados (não sabem). Começa-se com perguntas mais simples e, aos poucos, aumenta-se o grau de dificuldade" (Participante 47).

Observando os depoimentos dos licenciandos, evidencia-se a questão do uso de jogos, já mencionada anteriormente. Nesse sentido, três aspectos merecem atenção:

a) Nenhum dos professores aponta a criação de um jogo, todos fazem sugestões a partir de materiais prontos, principalmente o bingo e o uso de dados. Não se tem aqui a intenção de desvalorizar estes tipos de jogos, mas sim, questiona-se a criatividade e a adequação de acordo com a turma. Pois, "O ato criador abrange [...] a capacidade de compreender; e esta, por sua vez, a de relacionar, ordenar, configurar, significar" (OSTROWER, 2004, p. 9). Dessa forma, a criação de materiais didáticos poderia facilitar o trabalho do professor no sentido de instigá-lo à reflexão, permitindo liberdade de adequar a atividade de acordo com cada contexto de sala de aula.

b) Constam várias atividades envolvendo a questão do corpo como elemento da aprendizagem, podendo citar como exemplo a introdução da Educação Musical (Participante 45) conjuntamente à Matemática. Envolver a criança por inteiro na atividade proporciona não somente o desenvolvimento intelectual, mas habilidades motoras, muitas vezes delegadas apenas às atividades relacionadas à disciplina de Educação Física. Trabalhar utilizando-se da música vai ao encontro com os entendimentos de llari (2003, p. 14) afirmando que:

Quando a criança está em idade escolar, o aprendizado musical, além de ter valor em si mesmo, também exerce uma segunda função, que é ensino e o aprendizado de conceitos, 
ideias, formas de socialização e cultura, sempre através de atividades musicais.

Portanto, a Educação Musical pode atuar como um facilitador da aprendizagem da Matemática, auxiliando na memorização e compreensão de alguns conceitos. Nas questões relativas ao material concreto, os futuros professores mencionam empregar objetos da própria realidade do aluno, sendo possível destacar dois aspectos: a) formar conjuntos, contagem de materiais escolares, (Participantes 1, 6, 7, 36, 39, 48). Exemplificando: "troca de objetos usados pelos alunos no dia a dia escolar, tempo transcorrido ou faltante para o término da aula ou para o lanche, idade dos alunos família" (Participante 7). b) abordar aspectos externos à sala de aula. Questões estas que enfatizam elementos culturais dos estudantes e suas realidades cotidianas (Participantes 7, 33, 37, 52, 55, 57 63). Exemplificando: "[...] aprendem brincando como utilizar, como valorizar o dinheiro, enfim, em uma situação problema que com certeza vivenciam em família" (Participante 63). "[...] Valorização dos conhecimentos culturais [...]" (Participante 52). De acordo com Sebastiane Ferreira (1993), a escola está inserida num contexto social, seja ele o bairro, a aldeia, ou qualquer que seja seu entorno e, cabe ao professor, procurar lançar mão de atividades que podem ser desenvolvidas utilizando elementos próprios desses ambientes, visto que cada estudante carrega consigo raízes culturais que provêm de sua casa, desde o nascimento, afirma Madruga (2014).

Também se observa as variadas situações problema que podem ser geradas a partir do uso de materiais concretos, tais como brincadeiras que simulem um supermercado, venda dos brinquedos expostos em sala de aula, comparações entre os materiais escolares para possíveis agrupamentos. As situações citadas pelos licenciandos, porém, não evidenciam quanto às decisões em resposta aos dados levantados. Também é interessante pensar que outras questões podem estar envolvidas nestas situações e que por vezes extrapolam os conteúdos matemáticos, mas que nem por isso devem 
deixar de serem refletidas, tais como consumismo, a cooperação entre os estudantes, o valor atribuído ao dinheiro na sociedade, etc.

\title{
- Reflexão sobre as práticas
}

Além de sugestões, os futuros professores procuraram expressar suas reflexões, indicando alguns obstáculos e alternativas para utilização dos materiais concretos e jogos.

\begin{abstract}
"Acredito que podemos além desses recursos utilizar ferramentas tecnológicas como jogos de computador com estímulos sonoros e visuais para que a criança se divirta brincando e continue levando esses conceitos matemáticos além da sala de aula" (Participante 5).
\end{abstract}

"Dependendo da realidade local e regional, as escolas sofrem com falta de materiais alternativos e lúdicos para trabalhar certos conteúdos" (Participante 7).

"Os palitos coloridos podem ser utilizados de forma interdisciplinar ao mesmo tempo em que utiliza para operações matemáticas, também pode falar sobre as cores primárias e secundárias". (Participante 16).

"Dividindo os alunos em equipes e dando um suporte devido a cada um e suas necessidades" (Participante 18).

"Os jogos de Matemática são fundamentais para a construção de uma aprendizagem mais fácil sobre os números e as operações matemáticas, pois além de facilitar o aprendizado, possibilita a ampliação do pensamento lógico-matemático, necessário para os anos escolares seguintes. Alguns jogos são bem conhecidos e também de fácil acesso a qualquer criança em idade escolar, como o dominó, dados, contagem de peças ou unidades, atividades de somar e subtrair com cartões e desenhos e reconhecimento dos números e a ordem numérica" (Participante 8).

"Dependendo da região, pode-se trabalhar com elementos que façam parte da realidade local. Tais elementos podem dizer respeito a brinquedos ou objetos. Daí é possivel propor o lúdico, ou seja, brincadeiras nas quais os alunos, em grupos, por exemplo, possam apontar a perda ou o acréscimo de objetos. Podem ainda refletir sobre a possibilidade de agrupamentos desses elementos, descrever suas características e compará-los entre si" (Participante 37).

"A Matemática sendo uma ciência exata, está presente na vida do educando em todas as atividades do dia a dia. Entretanto, é tarefa do educador mostrar a importância que ela exerce, desde uma simples receita culinária até a compra em um supermercado, onde são utilizados dados numéricos que influenciam na motivação de aprender, pois são métodos lúdicos onde o educando vivencia as experiências no ambiente familiar e que pode ser compartilhadas 
em sala de aula com a produção de uma receita e em seguida fazer a degustação" (Participante 54).

É importante que o futuro professor compreenda e pondere sobre o uso de materiais concretos no ensino e aprendizagem de Matemática nos anos iniciais, bem como sobre a elaboração e decisões a partir dos dados observados no diagnóstico. Pois, o professor tendo em mãos este material avaliativo, pode refletir sobre sua prática pedagógica, e decidir quais as melhores maneiras de encaminhar suas ações, ambicionando o crescimento da turma e dos estudantes individualmente. De acordo com Anderson Moço (2010), o produto final do diagnóstico é uma espécie de mapa, que pode apontar as questões mais deficitárias da turma ou a que estudantes o professor deve dar mais atenção. Reafirmando as ideias de Santos e Varela (2007), dispor de resultados de uma avaliação diagnóstica implica numa tomada de decisão do professor sobre que direcionamentos pretende para o seu trabalho educativo.

O emprego de recursos tecnológicos como aplicativos, jogos eletrônicos, dentre outros, como sugerido pelo Participante 5, estabelecem uma alternativa para realização do diagnóstico. A facilidade com que muitos estudantes utilizam essas ferramentas permitem demonstrar conhecimentos que podem passar despercebidos pelo professor com o uso de materiais mais convencionais. Porém, não deve se limitar a utilização como único recurso, sendo apenas mais uma possibilidade a ser adotadas pelo professor para essa investigação.

Outro aspecto que emerge dentre as respostas é a importância da contextualização, valorização cultural e elementos regionais do cotidiano. Aproximar a Matemática do dia a dia dos estudantes parece ser um consenso entre os professores, demonstrando a preocupação de desmistificar a disciplina como algo distante da realidade e penosa de ser aprendida. Contextualizar, como dito pelo Participante 54 "[...] é tarefa do educador é mostrar a importância que ela [Matemática] exerce, desde uma simples receita culinária até a compra de um supermercado". O estudante 
participa em seu contexto familiar, mesmo de forma indireta, dessas tarefas rotineiras. Expor a ele a Matemática do cotidiano pode auxiliar com aspectos introdutórios ao diagnóstico, rememorando e esclarecendo. Também é fundamental que o professor ao expor aspectos ligados à Matemática demonstre ao estudante que a disciplina não está descontectada das outras, permeando e constituindo o conhecimento como um todo e não de forma fragmentada e isolada, facilitando a compreensão e aproximando essas aprendizagens à realidade.

A utilização de materiais alternativos ou mesmo um trabalho integrado à Educação Musical deve ser uma decisão do docente, na medida em que conhece sua turma, suas necessidades e as possibilidades a que pode lançar mão. O apoio dos demais colaboradores da escola também é importante, pois, muitas vezes, o professor necessita de recursos além da sala de aula. O compartilhamento de experiências entre pares pode auxiliar na melhoria de sua prática pedagógica.

\section{CONSIDERAÇÕES FINAIS}

Este artigo teve como objetivo analisar como grupo de estudantes de um curso de Licenciatura em Pedagogia na modalidade EaD de uma universidade privada do Sul do Brasil compreende os conhecimentos prévios das crianças, no ensino de Matemática nos anos iniciais e que possíveis caminhos apontam para esse diagnóstico. Com base nos depoimentos de 70 licenciandos, constatou-se que há uma homogeneidade em declarar a importância do diagnóstico inicial para o professor, por meio da utilização de materiais concretos, principalmente jogos para sua investigação. Observou-se ainda indicação do emprego de recursos tecnológicos, músicas e elementos do cotidiano dos estudantes - sejam do uso corrente em sala de aula ou fora dela.

A partir da análise, percebeu-se que o professor reconhece a necessidade de diagnosticar o que a criança já sabe, os conhecimentos que traz consigo resultantes de suas vivências e experiências, no entanto, o 
licenciando não compreende ainda como proceder com as informações decorrentes desse diagnóstico. Há uma tentativa da construção da avaliação diagnóstica por meio da utilização de materiais concretos, destacando-se nos depoimentos a recorrência dos jogos como alternativa pedagógica nessa tarefa investigativa.

Estes resultados (vale destacar que esses dados em um processo construtivo de conhecimento nunca são definitivos) devem indicar ao docente inicialmente que ele se veja como um pesquisador - identificando as dificuldades dos estudantes, as habilidades e que novos desafios devem se lançar; percebendo-se como um sujeito a que também merece ser avaliado (qual será o caminho mais fácil para que os estudantes aprendam? Será que a dificuldades dos estudantes é devida alguma falha em minha metodologia?) - e, também, como um sujeito mediador (o estudante deve ser o protagonista desse processo, que meios eu, enquanto docente, proporciono ao estudante para que ele produza seus conhecimentos?). Portanto, a avaliação diagnóstica não deve ser vista como um fim, mas como um meio de fornecer subsídios para a construção pedagógica.

Foi perceptível também a ausência de reflexão por parte dos licenciandos sobre as potencialidades e os diferentes caminhos que podem ser adotados a partir do diagnóstico. A realização de uma avaliação pelo simples cumprimento do dever agrega pouco valor. É necessário que o docente tenha consciência que o mapa elaborado a partir dos diagnósticos é capaz de direcionar suas aulas e apontar as dificuldades dos estudantes que mais necessitam de sua atenção.

Com base nos depoimentos dos graduandos/professores, constatou-se a necessidade de um olhar mais atento para o diagnóstico no processo formativo docente, para que na sua futura atução profissional consigam não só realizá-lo adequadamente, mas também utilizar os resultados para aperfeiçoamento de sua prática pedagógica, auxiliando-os nas escolhas dos caminhos os quais deverão ser seguidos, principalmente atendendo às necessidades de seus estudantes. 
Dessa forma, este artigo indica que há necessidade de mais produções que investiguem a formação inicial de professores dos primeiros anos do Ensino Fundamental, em especial no que se refere ao ensino da Matemática e ao diagnóstico inicial dos estudantes. Questões como: qual a real importância do diagnóstico em Matemática para a prática do professor dos anos iniciais? E ainda: como o professor deve proceder com os resultados destes diagnósticos? $\mathrm{E}$, qual o real objetivo da utilização de jogos no processo de avaliação inicial/diagnóstica? De que forma a Educação Musical e os recursos tecnológicos podem ser empregados na investigação inicial sobre os conhecimentos dos estudantes? São perguntas que instigam outras investigações.

Não foram realizadas entrevistas com os graduandos/professores posteriormente às postagens, o que impossibilitou que alguns pontos fossem melhores esclarecidos como, por exemplo, qual a finalidade do jogo no diagnóstico? Não há uma resposta a esta indagação, mas pelas falas dos cursistas, constatou-se que não há um objetivo concreto. Há a necessidade destes retratos dos conhecimentos dos estudantes, e este pode ser feito por meio de jogos e outros materiais, mas não há explicitado um objetivo para isso e, talvez, por esse motivo, o professor não saiba o que fazer com o mesmo.

É importante que o processo de formação inicial nas licenciaturas encaminhe cada vez mais ao movimento reflexivo da prática, indicando que é necessário o sujeito pensar sobre o que faz e para que fez, a fim de que seu fazer pedagógico não seja um simples ato reprodutivo de outras experiências. Permitir-se criar e lançar mão das diversas opções metodológicas e de recursos, de forma consciente torna o professor autônomo e produtor de novas aprendizagens, não apenas aos estudantes, mas sobre sua própria docência. 


\section{REFERÊNCIAS}

ALARCÃO, I. Professores Reflexivos em uma escola reflexiva. $8^{a}$ ed. São Paulo: Cortez, 2011.

ALVES, C. MORAIS, C. M. Recursos de Apoio ao Processo de Ensino e Aprendizagem da Matemática. In: VALE, I.; PIMENTEL, T.; BARBOSA, A.; FONSECA, L.; CANAVARRO, P. (org.). Números e álgebra: na aprendizagem de matemática e na formação de professores. Lisboa: Sociedade Portuguesa de Ciências da Educação, 2006, p.335-349.

BOGDAN, R.; BIKLEN, S. Investigação Qualitativa em Educação. Porto, Portugal: Editora Porto, 1994.

BOGGINO, N. A avaliação como estratégia de ensino: Avaliar processos e resultados. Revista de Ciências da Educação, n. 09, p. 79-86, 2009.

BOTTAS, D.; MOREIRA, D. A utilização dos materiais didáticos nas aulas de Matemática - Um estudo no $1^{\circ}$ Ciclo. Revista Portuguesa de Educação, v. 26, n. 1, p. 253-286, 2013.

BRASIL. Base Comum Curricular Nacional. Ministério da Educação. Proposta Preliminar - $2^{a}$ versão revista. Brasília: MEC, 2016.

BRASIL. Pacto Nacional para alfabetização na idade certa. Unidade 4, ano I, 2012.

FREIRE, P. Pedagogia da Autonomia: saberes necessários à prática docente. 50. ed. São Paulo: Paz e Terra, 2015.

ILARI, B. A música e o cérebro: algumas implicações do neurodesenvolvimento para a educação musical. Revista da ABEM, Porto Alegre, v. 9, p. 7-16, 2003.

IMBERNÓN, F. Formação permanente do professorado: novas tendências. São Paulo: Cortez, 2009.

LOPES A. J. Os saberes das crianças como ponto de partida para o trabalho pedagógico. In: BRASIL. Pacto Nacional pela Alfabetização na Idade Certa. Ministério da Educação. Secretaria de Educação Básica. Diretoria de Apoio à Gestão Educacional. Brasília: MEC, 2014, p.33 - 38.

LUCKESI, C. C. Avaliação da aprendizagem escolar. $13^{a}$ ed. São Paulo: Cortez, 2002.

MADRUGA, Z. E. F. Etnomatemática e modelagem matemática: Um estudo comparativo com os processos de criação de alegorias de carnaval. Revista Latinoamericana de Etnomatemática, v. 7, n. 1, p. 74-95, 2014.

MIRAS, M. Um ponto de partida para a aprendizagem de novos conteúdos: os conhecimentos prévios. In: COLL et al. (org.) O construtivismo na sala de aula. $4^{a}$ ed. São Paulo: Ática, 1998. p. 58-77.

MORAES, R.; GALIAZZI, M. C. Análise Textual Discursiva. $2^{a}$ ed. ljuí: Editora Unijuí, 2013. 
MOÇO, A. Você sabe o que eles já sabem? Nova Escola, n. 229, 2010.

NÓVOA, A. Os professores e a sua formação. 1992. Disponível em: <http://repositorio.ul.pt/bitstream/10451/4758/1/fdp-a-novoa.pdf.>. Acesso em: 15 nov. 2015

OSTROWER, F. Criatividade e processos de criação. $18^{a}$ ed. Petrópolis: Vozes, 2004.

PERRENOUD, P. A prática reflexiva no ofício do professor: profissionalização e razão pedagógica. Porto Alegre: Artmed, 2002.

POZO, J. I. A aprendizagem e o ensino de fatos e conceitos. In: COLL, C.; POZO, J. I.; SARABIA, B.; VALLS, E. Os conteúdos na reforma: o ensino e aprendizagem de conceitos, procedimentos e atitudes. Porto Alegre: Artmed, 1998. p. 17-70.

SANTOS, M. R.; VARELA, S. A avaliação como um instrumento diagnóstico do conhecimento nas séries iniciais do ensino fundamental. Revista Eletrônica de Educação, ano 1, n. 1, p. 1-14, 2007.

SEBASTIANE FERREIRA, E. Cidadania e Educação Matemática. A Educação Matemática em Revista, Blumenau, v. 1, n. 1, p. 12-18, 1993.

SOLÉ, I.; COLL, C. Os professores e a concepção construtivista. In: COLL, C. et.al. O Construtivismo na sala de aula. $4^{\mathrm{a}}$ ed. São Paulo: Ática, 1998. p. 9-29.

SOBRAL, A. C. M. B., TEIXEIRA, F. M. Conhecimentos Prévios: investigando como são utilizados pelos professores de ciências nas séries iniciais do ensino fundamental. In: VI ENPEC - Encontro Nacional de Pesquisa em Educação em Ciências, 2007, Florianópolis. Anais ABRAPEC- Associação Brasileira de Pesquisa em Educação em Ciências, 2007. v. 1. p. 1-11.

Recebido em: Março de 2017

Aceito em: Junho de 2017 